\title{
MEASUREMENT OF TECHNICAL EFFICIENCY AND ITS DETERMINANTS IN COTTON PRODUCTION IN NORTH- WEST, NIGERIA.
}

\author{
A.U. Babangida ${ }^{1}$, Yusuf, $\mathrm{O}^{2}$ and O. O. Ugbabe $^{2}$ \\ 1. Department of Agricultural Technology, Hassan Usman Katsina Polytechnic, Katsina State, Nigeria \\ 2. Department of Agricultural Economics, Institute for Agricultural Research, Ahmadu \\ Bello University, Zaria, Nigeria
}

\begin{abstract}
This study was designed to measure the technical efficiency and its determinants in cotton production in North West, Nigeria. The study used primary data generated during the 2013/2014 cotton production season. Data were collected through the use of structured questionnaire administered to 355 cotton farmers. The data were analyzed using stochastic frontier production model. Multi stage purposive sampling technique was used to select the States, the Agricultural Development Project zones, the Local Governments and the villages, while random sampling was used to select the respondents from which input-output data were collected. The result of the overall elasticities of production which give the level of return to scale derived from the Cobb-Douglas equation was 0.68 . The result of the study further shows that $30 \%$ of the farmers had technical efficiency of 0.81 and above while $70 \%$ of the farmers operate at less than 0.8 efficiency level. The farmers with the best and least practice had a technical efficiency of 0.99 and 0.10 , while the average technical efficiency index was 0.65 respectively. This implies that on the average, output fall by $35 \%$ from the maximum possible level due to inefficiency. The result of the determinants of technical inefficiency shows that the coefficients for age and farming experience were significant at $1 \%$.level of probability, while educational level, household size and marital status were negative and not significant.
\end{abstract}

Keywords: Technical Efficiency, Determinants of Technical Inefficiency, Cotton Production

\section{Introduction}

Cotton (Gossypium spp) is one of the most important vegetable natural fiber crops. It is one of the most important sources of income for smallholder farmers in many of the arid and semi-arid regions of Africa (UNDP, 2012). It is the number one natural fiber crop, used in textiles and it plays a very great role in international trade. It is a soft fiber shrub, native to tropical and sub-tropical regions around the world including America, India, and Africa (Idem, 1999). The largest volume of cotton production in the world is concentrated in countries like China, United States, India, Pakistan and Brazil. These countries produced more than three quarters of world output. However, low-income countries like Nigeria also depend on cotton to earn foreign exchange (Anderson and Valenzuela, 2006).

The role of the crop in the economy of West and Central Africa has been very prominent. It contributes $1.3 \%$ of Gross Domestic Products (GDP) in Cameroun, 8.8\% in Benin Republic and 5\% in Nigeria (Levi, 2010; Fortucci, 2012; and Huseyn, 2014). Hussein (2010) observed that cotton has been at the heart of an agricultural revolution in cotton-producing countries in West and Central Africa. Although cotton production in Africa is not significant on a global scale, a large number of African countries remained heavily dependent on cotton. For instance, cotton accounts for $60 \%$ of foreign exchange earnings in Benin. The West and Central African producers, which had a very marginal rank in the world market forty years ago, have considerably increased

Corresponding Author: A.U. Babangida Conference Proceedings / abdubau@gmail.com 


\section{A.U. Babangida 1 , Yusuf $O^{2}$ and O. O. Ugbabe $e^{2}$ Measurement of Technical Efficiency and its Determinants in Cotton Production in North-West, Nigeria}

their production capacity, and now account for more than one million tons, representing over $4 \%$ of the world production (ICAC, 2013). Between 1990 and 2007, West African cotton yield per hectare was approximately 1.1 tons (FAOSTAT, 2010). The area put under cotton production in West Africa and Central Africa has been estimated to be 2.4 million hectares (Alam et al., 2013).

Cotton is grown as a cash crop by about 0.8 million farmers on a total estimated area ranging from 0.6 0.8.million hectares (Gbadegesin et al., 2007). The major feature of cotton production in Nigeria is that about $80 \%$ of total production is by peasant farmers under rainfed conditions with simple tools and animal drawnimplements (Adeniji, 2007). This has resulted in farmers in tropical Africa usually obtaining low yields averaging 300 and 500 kilogram per hectare of seed cotton. World average yield of cotton is about 1.5 tons per hectare (International Cotton Advisory Committee, 2013). In the year 2014, the average Nigeria yield is 232 kilogram per hectare (USDA, 2014)

Statistics on Nigerian cotton production and yield shows significant fluctuation, but on average it is on a downward trend over the last twenty years. The peak period of cotton production in Nigeria was the year 1995 when 459,000 bales $(183.45 \mathrm{~kg} / \mathrm{bale})$ at a growth rate of $53.51 \%$ and a corresponding peak period of yield record of $454 \mathrm{~kg} / \mathrm{ha}$ representing a growth rate of $46.45 \%$. Thereafter production started declining to the current production status of 320,000 bales ( $6.6 \%$ growth rate) and yield states of $232 \mathrm{~kg} / \mathrm{ha}$ ( $3.11 \%$ growth rate) which is about half the figures of 1995. The impact of this is decline in foreign exchange, lack of raw materials for textiles and oil mills (ASDA, 2014).In the 1980s Nigeria earned over 8.9 billion US dollars from cotton. This amount represented more than $25 \%$ of the nation's GDP. The country's earning from cotton however dwindled to a mere 300 million US dollars in 2013 (Huseyn, 2014).

This study is therefore very essential because of the immense contribution of cotton as a cash crop to the national economy of Nigeria. The increasing need for the country to diversify its economy and revenue base to non-oil alternatives, increasing demand for cotton lint and seed to meet the needs of textile and oil-processing and feed industries has made the study necessary as it would determine the efficiency of resources used with a view to making appropriate recommendations for increased cotton production. Furthermore, the research will serve as a "spring-board" for further research by public and private institutions particularly on the aspects not covered in this study. The outcome of the study should provide information on the state of efficiency with which cotton is being produced in Nigeria so that investors, donor agencies, none governmental organizations, development partners and private companies wishing to invest and sponsor intervention programs that will improve on the production efficiency and profitability of cotton farming decisions in the study area.

\section{Methodology}

\section{The study area}

The study area was the north-west agro-ecological zone of Nigeria which lies between latitudes $90 \mathrm{~N}$ and $140 \mathrm{~N}$ and longitudes $70 \mathrm{E}$ and 600E of the Greenwich Meridian. The zone comprises of seven States, namely, Jigawa, Kano, Katsina, Zamfara, Sokoto, Kebbi, and Kaduna. However, the study was conducted in only three States, namely, Kano, Katsina and Zamfara which are known for large-scale cotton production. The climate of the zone is essentially tropical climate, generally characterized by alternating wet and dry seasons with mean annual rainfall ranging from $500 \mathrm{~mm}$ to nearly $1200 \mathrm{~mm}$.

\section{Sampling procedure}

Multi-stage sampling technique was used to select respondents for this study. In the first stage, three States were purposively selected based on their scale of cotton production. The second stage involved a purposive selection of two Agricultural Development Project (ADP) Zones from each State. The ADP zones were selected based on 
their prominence in cotton production. In the third stage, two Local Government Areas were also purposively selected from each of the ADP Zones based on their scale of cotton production. In the fourth stage, two villages were purposively selected based on their prominence in cotton production from the selected Local Government Areas. Finally, a $15 \%$ proportionate random selection of cotton farmers was done from the selected villages given a total of 355 respondents.

\section{Sources of data}

The study used primary data. The primary data pertaining to this study were collected using structured questionnaire. The data was collected based on the 2013/2014 cotton cropping season. To facilitate the collection of the data, the services of agricultural extension agents was engaged. Some training was given to the extension agents to acquaint them with the content of the questionnaire. The data collected included:

(i) Socio-economic and institutional characteristics of the cotton farmers, for example, age, sex, educational level, family size, farming experience, marital status, access to credit, membership of cooperative societies and contact with extension agents.

(ii) Farm production and market information which included: farm size, hired and family used, fertilizer used, quantity of agrochemicals used, quantity of seed used, farm output, farm input costs, market prices of output, and constraints to cotton production.

\section{Analytical procedure}

In estimating the technical efficiency, the Cobb Douglass functional form of the stochastic frontier model was used as an economic method of efficiency measurement to achieve the objective of the study. It is specified as thus;

$\mathrm{LnYi}=\beta_{0}+\beta_{1} \operatorname{LnX}_{1}+\beta_{2} \operatorname{LnX}_{2}+\beta_{3} \operatorname{LnX} X_{3}+\beta_{4} \operatorname{LnX}_{4}+\mathrm{V}_{1}+\mathrm{U}_{\mathrm{i}}$

Where:

Ln = natural logarithm,

$\mathrm{Yi}=$ output of cotton from the $\mathrm{i}^{\text {th }}$ farmer in $(\mathrm{Kg})$

$\mathrm{X}_{1}-\mathrm{X}_{4}=$ quantity of inputs used,

$\beta_{1} \beta_{4} \quad=$ regression coefficients.

$\mathrm{Vi}=\mathrm{A}$ random variable in production which accounts for the random variation is output by factors beyond the control of farmers.

$\mathrm{Ui}=$ random variable called technical inefficiency effects,

$\beta_{0} \quad=$ intercept.

This was estimated by maximum likelihood estimation (MLE) technique available in the computer program called FRONTIER VERSION 4.1 developed by Coelli (1996).

When $\mathrm{TE}=1$, it shows that a farmer obtains maximum feasible output, while if $\mathrm{TE}<1$ means a shortfall of the observed output to the frontier output.

The study also identified the determinants of farmers' technical efficiency in terms of socio-economic and institutional variables. In this respect, an inefficiency model which assumes that the inefficiency effects are

independently distributed having $\mathrm{N}\left(\mathrm{O}, \ltimes^{2} \mathrm{u}\right)$ distribution and mean Ui. The model is specified as follows:

$\mathrm{Ui}=\alpha_{0}+\alpha_{1} \mathrm{~W}_{1}+\alpha_{2} \mathrm{~W}_{2}+\alpha_{3} \mathrm{~W}_{3}+\alpha_{4} \mathrm{~W}_{4}+\alpha_{5} \mathrm{~W}_{5}+\alpha_{6} \mathrm{~W}_{6}+\alpha_{7} \mathrm{~W}_{7}+\alpha_{8} \mathrm{~W}_{8}+\alpha_{9} \mathrm{~W}_{9}+\mathrm{Ei}$.

Where

$\mathrm{Ui}=$ technical inefficiency of the $\mathrm{i}^{\text {th }}$ farmer,

$\mathrm{W}_{1}$ - $\mathrm{W}_{9}$ Socio-economic variables,

$\alpha_{1}-\alpha_{9}=$ parameters to be estimated,

$\alpha_{0}=$ intercept, $\mathrm{E}_{\mathrm{i}}=$ error term 


\section{A.U. Babangida 1 , Yusuf $O^{2}$ and O. O. Ugbabe $e^{2}$ Measurement of Technical Efficiency and its Determinants in Cotton Production in North-West, Nigeria}

The variances of the random errors, $\delta^{2} \mathrm{~V}$, and that of technical inefficiency effects, $\delta^{2} \mathrm{U}$, as the overall variance of the model, $\delta^{2}$, are related as follows:

$\delta^{2}=\delta^{2} V+\delta^{2} U$, and the ratio $\alpha=\delta^{2} \mathrm{~V} / \delta^{2} \ldots \ldots \ldots . . .3$

\section{Results and Discussion}

The Maximum likelihood (ML) estimates and inefficiency determinants of the specified frontier are presented in Table 1. The study revealed that the generalized log likelihood function was -542.47 .. The value of gamma $(\gamma)$ is estimated to be $76 \%$ and it was highly significant at $1 \%$ level of probability. This is consistent with the theory that true $\gamma$-value should be greater than zero. This implies that $76 \%$ of random variation in the yield of the farmers was due to the farmers' inefficiency in their respective sites and not as a result of random

variability. The value of sigma squared $\left(\delta^{2}\right)$ was significantly different from zero level of probability. This indicates a good fit and correctness of the specified distribution assumptions of the composite error terms. This means that the inefficiency effects make significant contribution to the technical inefficiencies of cotton farmers.

However, the estimated coefficients of all parameters of production function were positive. Seed and fertilizer were positive and significant at $1 \%$ level of probability, while the coefficient of agrochemical was positive at $5 \%$ and hence play a major role in cotton production in the study area. The average technical efficiency for the farmers is 0.762 implying that, on the average the respondents are able to obtain $76 \%$ of potential output from a given mixture of production inputs. Thus, in a short run, there is minimal scope $(24 \%)$ of increasing the efficiency, by adopting the technology and techniques used by the best cotton farmer.

The estimated coefficient for seed was 0.195 , which is positive and statistically significant at $1 \%$ level. The estimated elasticity of seed ( 0.195$)$ implies that increasing seed by $1 \%$ will increase cotton output by less than $1 \%$ which means, all things being equal the output is inelastic to changes in the quantity of seed used. This is in line with the findings of Shehu et al (2007) who observed that the estimated coefficient of seed was positive.

Table 1: Maximum Likelihood Estimation Result of the Stochastic Frontier Production Function

\begin{tabular}{lllll}
\hline Variables & Parameter & Coefficient & $\begin{array}{l}\text { Standard } \\
\text { Error }\end{array}$ & T-ratio \\
\hline Constant & $\beta_{0}$ & 8.853976 & 0.888785 & 9.961886 \\
\hline Seed & $\beta_{1}$ & $0.194643 * * *$ & 0.06151 & 3.164429 \\
\hline Fertilizer & $\beta_{2}$ & $0.357827 * * *$ & 0.105037 & 3.406666 \\
\hline Agrochemicals & $\beta_{3}$ & $0.1143^{* *}$ & 0.0553 & 2.065200 \\
\hline Labor & $\beta_{4}$ & 0.021469 & 0.030394 & 0.706335 \\
\hline Return to scale (RTS) & & $\mathbf{0 . 6 8}$ & 13.75777 \\
\hline Diagnostic statistic & & & & 1.937376 \\
\hline Sigma-squared $\left(\delta^{2}\right)$ & & $65.5 *$ & 0.516162 & \\
\hline Gamma $(\gamma)$ & & & & \\
\hline Log likelihood function & -542.47 & & & \\
\hline LR Test & 68.466 & & & \\
\hline Total number of observation & 355 & & & \\
\hline Mean efficiency & 0.762 & & & \\
\hline \multicolumn{1}{c}{$* * 0.10$} & & \\
\hline
\end{tabular}


Result of the overall elasticity of production is also determined and presented in Table 2. Elasticity of production is a useful guide that enhances farmers to be prudent and rational when allocating and utilizing inputs in production. The elasticities derived from the Cobb-Douglas equation was 0.68. This gives the return to scale which was obtained from the summation of the coefficients of the estimated input elasticities. Since this value $(0.68)$ was less than 1 , it shows that it is a positive decreasing return to scale at stage II of production process where every farmer strives to maximize profit and minimize cost of production. The result also shows that if all the inputs included in the production function model are increased by $1 \%$, cotton output will increase by $0.68 \%$

Table 2: Elasticity of Production and Return to Scale in Cotton Production

\begin{tabular}{lll}
\hline Variables & Parameter & Coefficient \\
\hline Seed & $\beta_{1}$ & $0.194643^{* * *}$ \\
\hline Fertilizer & $\beta_{2}$ & $0.357827^{* * *}$ \\
\hline Agrochemicals & $\beta_{3}$ & $0.1143^{* *}$ \\
\hline Labour & $\beta_{4}$ & 0.021469 \\
\hline Return to scale (RTS) & & $\mathbf{0 . 6 8}$ \\
\hline
\end{tabular}

The production elasticities of output with respect to quantity of seed and fertilizer were 0.2 and 0.4 which were all positive and statistically significant at $1 \%$ level (Table 1and 2). This implies that a $1 \%$ increase in seed and fertilizer will increase cotton output by 0.2 and $0.4 \%$. The coefficient of fertilizer also has the highest value. This indicated that fertilizer devoted to cotton production was the most important input to which output was responsive because it has the highest elasticity.

The coefficient of agro-chemical was 0.11 which was positive and statistically significant at $5 \%$ level and has the expected positive sign, which is in conformity to a priori expectation.

The coefficient for labor was positive and significant at $5 \%$ and has the expected positive sign. This implies that labor positively influences the output of cotton farmers in the study area especially human labor that plays a crucial role in virtually all farming activities. This situation has been attributed to split-plot cropping on small scattered land holdings and lack of affordable equipment (Umoh, 2006)

\section{Frequency Distribution of Technical Efficiency Estimates of Cotton Farmers}

The frequency distribution of the technical efficiency estimates for cotton farmers in the study area as obtained from the stochastic frontier model presented in Table 3. It was observed that the average technical efficiency levels is 0.65 ranging from 0.10 to 0.99 , while the maximum and minimum was 0.99 and 0.10 This is comparable to the study of. Adzawla et al., (2013) in their study on technical efficiency of cotton production in Yendi Municipality, northern Ghana who had mean maximum and minimum technical efficiency estimates of $0.88,0.99$ and 0.70 . Similarly, Tsimpo,(2010) in his study on technical efficiency and optimal farm size in the Jajik's cotton sector found a mean technical efficiency of 0.67.Neba et al.,(2010) had also a similar finding (mean technical efficiency of 0.83 ) in their study on determinants of technical efficiency of cotton farmers in northern Cameroon.

The result of the study in Table 3 shows that $30 \%$ of the farmers had technical efficiency (TE) of 0.81 and above while $70 \%$ of the farmers operate at less than 0.8 efficiency level. The result of the mean technical efficiency of the farmers implies that, on average $65 \%$ of output was obtained from the given mix of production inputs by farmers, while cotton output of farmers have fallen by $35 \%$,otherwise there is potential for increasing output by $35 \%$ through the adoption of efficient farming practices.

The results also suggests that for the average farmer in the study area to achieve technical efficiency of his most efficient counterpart, he could realize about 35per cent $(1-0.65 / 0.99 \times 100)$ cost savings while on the other hand, the least technically efficient farmers will have about 91 per cent $(1-0.10 / 0.99 \times 100)$ cost saving to become the most efficient farmer. The fact that the technical efficiency of all sampled farmers is less than 1 , implies that no farmer reached the frontier

. Table 3: Frequency distribution of technical efficiency estimates 


\section{A.U. Babangida ${ }^{1}$, Yusuf $O^{2}$ and O. O. Ugbabe ${ }^{2}$ / Measurement of Technical Efficiency and its Determinants in Cotton Production in North-West, Nigeria}

\begin{tabular}{lcr}
\hline Technical efficiency & Frequency & Percentage \\
\hline $0.10-0.20$ & 7 & 1.972 \\
\hline $0.21-0.40$ & 50 & 14.085 \\
\hline $0.41-0.60$ & 70 & 19.718 \\
\hline $0.61-0.80$ & 122 & 34.366 \\
\hline $0.81-1.00$ & 106 & 29.859 \\
\hline Total & 355 & 100 \\
\hline Average & 0.646681 & \\
\hline Maximum & 0.994639 & \\
\hline Minimum & 0.10338 & \\
\hline
\end{tabular}

\section{Determinants of technical inefficiency}

Table 4 shows the estimated determinants of technical inefficiency in cotton production in North-West Nigeria. It should be noted that the socio-economic and institutional variables used in the technical efficiency model are the determinants of inefficiency and not efficiency. This implies that a negative sign on a parameter means that the variable reduces technical inefficiency and increases technical efficiency, while a positive sign means a variable increases technical inefficiency and thus reduces technical efficiency.

The coefficient for age in this study was positive and significant at $1 \%$ level of significant. This shows that increase in age increases technical inefficiency. This is similar to the findings of Adzawla et al (2013). Valino and Fleming (2006) in their estimation of excess water use in irrigated agriculture using data envelopment analysis in Punjap found that older farmers were less willing to adopt better practices and less willing to take risks of adopting new innovations and hence more technically inefficient. This is in contrast to the findings of several studies including that of Neba et al (2010) and Gul et al (2009) who found age to be negatively related to technical inefficiency. The possible reason given may be due to the fact that as the farmers advance in age, inefficiency in resource uses decreases, while technical efficiency increases.

Household size showed a negative relationship with predicted technical inefficiency and is not significant. This implies that farmers who have large household sizes are more technically efficient. The reason for this relationship is that as the number of people in a household increases, a pool of family labor becomes available and this leads to specialization.

Education showed a negative relationship with technical inefficiency and is not significant. The negative coefficient of education reveals that the level of education results in reduction in technical inefficiency of cotton farmers. This is in accordance with a priori expectation. Educated farmers are able to gather, understand and use information from research and extension more easily than illiterate farmers. Moreover, educated farmers are likely to be less risk-averse and therefore more willing to try out modern technologies. Kehinde and Awotido (2012) in their study on production efficiency of mechanized arable farming in Osun State, Nigeria observed that education sharpens managerial input and leads to a better assessment of the importance and complexities of good decisions in farming.

The coefficient for extension contact was negative and significant at $1 \%$ level. Access to extension services increases the level of cotton farmers' availability of information about technical aspects of crop technologies that play an important role in increasing farm level efficiency. The availability of an extension worker in the community and the usefulness of the extension messages (as perceived by the respondents) are significant determinants of technical efficiency. Furthermore, farmers who are members of extension-related organizations exhibit higher levels of efficiency. For instance, Asongwa et al. (2011) in the analysis of the efficiency of Nigerian small-scale farmers in Benue State, Nigeria observed that a marginal increase in access to extension contact of households resulted in $22.23 \%$ decline in technical inefficiency among the respondents. In some cases extension agent are also the channels of input supply to rural farmers. For extension contact to achieve the desired impact in improving technical efficiency, the farmers must be able to adopt the improved technology to their local situation. 
The coefficient of cooperative membership was positive and significant at $1 \%$. This is also contrary to a priori expectation as reported by Odedokun (2014). The reasons might be that although farmers belong to a cooperative association, they do not derive any benefit from their membership, but rather tie down their resources and end up being used in unprofitable ventures. It also shows that membership of cooperative association does not favor cotton marketing or cheap input procurement at all.

The coefficient for farming experience (number of years in cotton production) was negative and significant at $10 \%$. This shows that it increases technical efficiency and decreases technical inefficiency. This is similar to findings of Adzwala et al. (2013) This was perhaps due to the ability of experienced farmers to draw on past experiences to suit their farming condition. The availability of an extension worker in the community and the usefulness of the extension messages (as perceived by the respondents) are significant determinants of technical efficiency. Furthermore, farmers who are members of extension-related organizations exhibit higher levels of efficiency. For instance, Asongwa et al. (2011) in the analysis of the efficiency of Nigerian small-scale farmers in Benue State observed that a marginal increase in access to extension contact of households resulted in $22.23 \%$ decline in technical inefficiency among the respondents. In some cases extension agent are also the channels of input supply to rural farmers. For extension contact to achieve the desired impact in improving technical efficiency, the farmers must be able to adopt the improved technology to their local situation

The coefficient of access to credit was negative and significant at $1 \%$. This is in accordance with a priori expectation, because credit is believed to increase crop area, more input application and more yields. Yessin (2004) in his study observed that farmers who are not constrained by credit are more technically efficient than those who are. It must however be noted that for access to credit to positively affect technical efficiency, the credit has to properly managed and sound agronomic practices has to be adopted (Adejoh, 2010). To be more effective in increasing farmers' productivity, it is suggested that institutional credit should be of low interest rate, procedures of advancing loan should be made simple to peasant farmers and credit should be made available on time (Shah et al., 2008).

The co-efficient of marital status was negative and not significant. This shows that marital status reduces technical inefficiency and increase technical efficiency. This disagrees with Rahman and Umar (2009) in their study who found marital status to be positive and significantly related to technical efficiency. The coefficient of Gender Dummy (male=1) was negative and not significant. This shows that women farmers can produce Cotton more efficiently than men. This disagrees with the finding of Rahman and Umar (2009) in their study on measurement of technical efficiency and its determinants in crop production in Lafia local government, Nasarawa State, Nigeria.

Table 4: Estimated determinants of technical inefficiency

\begin{tabular}{lllll}
\hline Variable & Parameter & Coefficient & Standard error & T-value \\
\hline Constant & $\mathrm{Z}_{0}$ & 0.819296 & 0.19801 & 4.138 \\
\hline Age & $\mathrm{Z}_{1}$ & $0.002532^{*}$ & 0.001347 & 1.88 \\
\hline Education & $\mathrm{Z}_{2}$ & -0.00871 & 0.009596 & -0.907 \\
\hline Access to credit & $\mathrm{Z}_{3}$ & $-0.155505^{* * *}$ & 0.041674 & -3.731 \\
\hline Household size & $\mathrm{Z}_{4}$ & -0.00017 & 0.000151 & -1.124 \\
\hline Cooperative membership & $\mathrm{Z}_{5}$ & $0.008745^{* * *}$ & 0.001292 & 6.769 \\
\hline Extension contact & $\mathrm{Z}_{6}$ & $-0.00119^{* * *}$ & 0.001663 & 0.715 \\
\hline Farming experience & $\mathrm{Z}_{7}$ & $-0.003^{*}$ & 0.001588 & -1.889 \\
\hline Marital status & $\mathrm{Z}_{8}$ & -0.11229 & 0.090538 & -1.24 \\
\hline Gender & $\mathrm{Z}_{9}$ & -0.03188 & 0.040713 & -0.783 \\
\hline
\end{tabular}

$* * * \mathrm{P}<0.01 \quad * * \mathrm{P}<0.05 \quad * \mathrm{P}<0.10$

\section{Conclusion}

The results from the production function showed that the major input variables influencing cotton output were seed, fertilizer and agro chemicals. These results imply that in order to improve output levels in cotton production there is need to increase seed quality, fertilizer and agro chemicals used. The results revealed that the 


\section{A.U. Babangida 1 , Yusuf $O^{2}$ and O. O. Ugbabe $e^{2}$ Measurement of Technical Efficiency and its Determinants in Cotton Production in North-West, Nigeria}

sum of the output elasticities with respect to all inputs is 0.69 . This is a positive decreasing return to scale at stage II of the cotton production process where every farmer strives to maximize profit and minimize cost. Furthermore, the estimated mean technical inefficiency in cotton production suggests that some scope exist for farmers to increase their levels of technical efficiency. Results of the determinants of technical inefficiency indicate that farmers' socio-economic variables should be considered as significant factors influencing inefficiency in cotton production. The conclusions from these findings are that there is ample opportunity to increase the present level of efficiency of cotton production in the study area. This can be achieved through improved farmer-specific factor which include educational level of farmers, access to credit, extension contact, and membership of cooperatives.

\section{Recommendations}

Based on the findings of this research, the following recommendations are made:

i. The positive and significant relationship between farm size, family labor and agrochemicals with output implies that increasing the levels of utilization of each of these inputs will result in an increase in the level of output of cotton. Farmers should therefore be encouraged to increase their use of these inputs to the recommended levels.

ii. Since the mean levels of technical (0.65) efficiencies was below the optimum level, there is scope for increasing the levels of technical 35 through the adoption of the best technologies or techniques in cotton production.

iii. Education was found to have contributed in increasing technical efficiency in cotton production in the study area. All policy measures that build the educational capacities of farmers and strengthen their managerial capacities will lead to a substantial reduction in technical inefficiency. For example, adult literacy programmes could be introduced in rural areas and agricultural sciences introduced as part of these programmes.

iv. The farmers should be encouraged to form goal driven cooperative groups and pool their resources together to improve upon their finances and bargaining powers in order to increase their output and income.

\section{References}

ADENIJI, O.B. 2007, Constraints to Improved Cotton Production in Katsina State,Nigeria. Journal of Applied Sciences. 7:1647-1651.

ADENIJI, O.B., and JIRGI, A. J., 2010, Cost and Returns analysis of Cotton production in Katsina State, Nigeria. Journal of Agriculture, Forestry and Social Sciences. 8(1): 34-44.

ADZAWLA,W., FUSEINI, J., and DONKOH, S.A., 2013, Estimating the Technical Efficiency of Cotton Production in Yendi Municipality, Northern Ghana. Journal of sustainable Development. 4(70):123-133.

AIGNER, D.J., LOVELL., C.A.K., and SCHMIDT, P., 1977, The formulation and Estimation of Stochastic Frontier Production Function Models. Journal of Econometric. 6:21 - 37.

AJIBEFUN, I.A., and ABDULKADRI, A.O., 2004, Impact of Farm Size on Resources Use Efficiency In Small Scale Farming; Evidence from the South-Western Nigeria. Journal of Food, Agriculture and Environment. 2(1):359-369

ALAM, M.K., ABOKI, E., GIDADO. E. H., and BUBA, D.D., 2013, Economic Analysis of cotton production in Selected Local Government Areas of Taraba State, Nigeria. Journal of Agricultural Science. 4(1) 27-39.

ANDERSON, K., and VALENZUELA, E., 2006, The World Trade Organization. Doha Cotton Initiative: A Tale of Two Issues. World Bank Policy Research Working Paper 3918, 2006. Washington DC

ASONGWA, A.D., JUDE, B.A., KEN, M.A., and EMMANUEL, J., 2011, An analysis of economic efficiency of Nigerian small-scale farmers in Benue State, Nigeria. Journal of Economic Development and Strategy. Vol.3, No. 11 
COELLI, T.J., 1996, A Guide to FRONTIER Version 4.1 A Computer Programme for Stochastic Frontier Production and Cost function Estimation CEPA Working paper 96/07.University of New England.

FORTUCCI, P., 2012, The contribution of Cotton to Economy and Food Security in Developing Countries: Note Presented at the Conference of Cotton and Global Trade Negotiations.

GBADEGESIN, J., ONYIBE, E., UYOVBISERE, E., and ADEOSUN, J. O., 2007, Cotton Production in Nigeria. A Publication of the Cotton Sector Development Programme, Cotton Development Committee.

GUL, M., KOC, B., DAGISTAN. E., and PARLAKAY, M., 2010, Determinant of Technical Efficiency in Cotton Growing Farms in Turkey: A Case Study of Cukuvora. African Journal of Agricultural Research. 4(10)

HUSEYN, M., 2014, Boosting Cotton production in Nigeria. People's Daily, May, 26, p7. www.peoplesdailyng.com. Retrieved on July, 11, 2014

IDEM, N. A., 1999, Cotton Production in Nigeria. (Barak Press and Publishers Limited, Kaduna, Nigeria, pp. 46 $-54)$.

INTERNATIONAL COTTON ADVISORY COMMITTEE (ICAC)., (2013). Cotton Statistics.

KEHINDE, J., and AWOTIDO A. C., 2012, Production Efficiency of Mechanized Arable Farming in Osun State, Nigeria. Journal of Agricultural Technology.

LEVI, A.. 2010, "Francophone Africa Cotton Update".In Proceedings of the Beltwide Cotton Conference. Memphis TN Vol. 1pp 269-271.

NEBA, C., NGASSAM, S., and NZOMO, J., 2010, The Determinants of Technical Efficiency of Cotton Farmers in Northern Cameroon. MPRA Paper No. 24814

ODEDOKUN, V.O., 2014, Economic Analysis of Cotton Production and Supply trend Estimation in Zamfara State, Nigeria. Unpublished Ph.D. Dissertation, Department of Agricultural Economics and Rural Sociology, Ahmadu Bello University Zaria, Nigeria. 244p

RAHMAN, S. A., and UMAR, H. S., 2009, Measurement of Technical Efficiency and its Determinants in Crop production in Lafia Local Government Area of Nasarawa State, Nigeria. Journal of Tropical Agriculture, Food, Environment and Extension. Vol 8. No.2

SHEHU, A.B., BALA, U.A., SUNDAY, A., and INUWA, B.U., 2007, Productivity and Technical efficiency of small-scale rice producers in Adamawa State, Nigeria. Journal of Sustainable Agriculture. Vol. 2, No. 5.

TSIMPO, C. N., 2010, The Technical Efficiency and Optimal Farm Size in the Jajik's Cotton Sector. MPRA paper No. 35192

UMOH, G.S., 2006, Resource Use Efficiency in Urban Farming. An Application of Stochastic Frontier Production Function. International Journal of Agriculture and Biology. 8 (1): 38 - 44. www. Fs publisher. Accessed on 17th July, 2013

UNITED STATE DEPARTMENT OF AGRICUlTURE., 2014, Nigeria Cotton Statistics. Www.indexmundi.com/agricuture. Accessed on 12th June, 2014

VALINO, R. A., and FLEMING, E. M., 2006, Technical inefficiency and production risk in rice 46. farming: Evidence from central Luzon Philippines', Asian Economic Journal, Vol.

20, pp. 29-

YASSIN, A.E., 2004, Economic Analysis of the Irrigated Cotton Production Constraints in Sudan. Case study of Gezira scheme. In Werner, D. and Siegfried, B.(eds). Farming and Rural Systems Economics, Volume 6i. Margraf Publisher Weikorsheim, Germany, pp.101. 